\title{
MAXILLARY SINUS LIFT WITH AND WITHOUT SELF HARDENING BIPHASIC CALCIUM PHOSPHATE AND SIMULTANEOUS IMPLANT PLACEMENT
}

\author{
Shaimaa A. El Sadek ${ }^{*}$ M.Sc., Ahmed A. A. Sharara ${ }^{2}$ PhD, Magda M. Sahleh ${ }^{3}$ \\ $\mathrm{PhD}$, Nevien Shawky $\mathrm{PhD}^{4}$
}

\begin{abstract}
INTRODUCTION: Resorption of the upper alveolar bone occurs due to loss of maxillary posterior teeth with subsequent pneumatization of the maxillary sinuses. This bone atrophy may jeopardize the osseointegration of dental implants, therefore it is recommended to increase the bone volume by augmentation of the maxillary sinus floor in order to allow dental implant placement. Sinus lift with biphasic calcium phosphate which is a reliable sinus grafting materials and sinus lift with blood clot only as filling material are two applicable modalities. Objectives: This study was carried out to compare the outcome of sinus lift without grafting material, versus the use of moldable, self hardening calcium phosphate biomaterials with simultaneous implant placement.

MATERIALS AND METHODS: This study was designed as a randomized controlled clinical trial, the study population consisted of 20 patients with missing maxillary posterior teeth and residual bone height 5-7mm. The sample was selected conveniently according to a list of inclusion and exclusion criteria, the participants were allocated randomly into two equal groups. All patients had sinus lift using piezosurgery device with simultaneous implant placement. In group I, no grafting material was used. In group II, moldable, self-hardening calcium phosphate was the filling material. Clinical and radiographic evaluations were done through 6 months postoperatively.

RESULTS: 6 months postoperatively, Cone beam computerized tomography showed insignificant difference between both groups regarding bone height, density and marginal bone loss.

CONCLUSION: The difference was insignificant regarding bone height, density and marginal bone loss between sinus lift with and without biphasic calcium phosphate.

KEYWORDS: Sinus lifting, Implants, Piezosurgery, Grafting materials.

1 M.Sc., 2009, Oral and Maxillofacial Surgery, Faculty of Dentistry, Alexandria University, Egypt.

2 Professor of Oral and Maxillofacial Surgery, Department of Oral and Maxillofacial Surgery Faculty of Dentistry, Alexandria University, Egypt.

3 Professor of Oral and Maxillofacial Surgery, Department of Oral and Maxillofacial Surgery Faculty of Dentistry, Alexandria University, Egypt.

4 Professor of Oral and Maxillofacial Surgery, Department of Oral and Maxillofacial Surgery Faculty of Dentistry, Alexandria University, Egypt.
\end{abstract}

\section{*Corresponding author}

E-mail: shaimaaelsadek@yahoo.com

\section{INTRODUCTION}

Nowadays, it has become a clinical routine to use dental implants for oral rehabilitation. Several studies have reported successful and promising results in patients with normal bone volume and density, which provide adequate standard diameter and length (1).

The loss of maxillary posterior teeth is the main cause for patients to require dental implants. There are two main reasons which make the rehabilitation of posterior maxilla difficult. First, after loss of maxillary posterior teeth, the alveolar ridge decreases by bone atrophy and resorbs vertically and horizontally $(2,3)$. Second, insufficient vertical bone volume on posterior maxilla results from pneumatization of the maxillary sinus and causes insufficient vertical bone volume on posterior maxilla (4). Hence, the placement of dental implants in the edentulous posterior maxilla is challenging due to deficient posterior alveolar ridge (1).
The sinus floor augmentation or sinus lift technique was introduced to increase the vertical bone level in order to secure primary stability of the endosseous implants (5).Maxillary sinus augmentation through the lateral window approach was developed to allow placing of implants in the maxillary posterior edentulous sites which shows significant pneumatization of the maxillary sinus $(6,7)$.This technique is considered one of the most applicable treatment modalities for the augmentation of the maxillary sinus (8). Placement of implants simultaneously with the lateral window sinus augmentation technique showed high success rates that are reported to be similar to implants placed in the maxillary pristine bone (9).

A 1-stage or 2-stage implant placement approach has been performed together with lateral wall maxillary sinus augmentation procedures. Traditionally, the main pre-requisite for implant placement, simultaneously with direct sinus lift, has been native vertical bone height 
El Sadek et al.

$(\mathrm{VBH})>4 \mathrm{~mm}$ or at least $5 \mathrm{~mm}$ as measured preoperatively (10).

Recent clinical studies suggests that direct sinus lift in ridges with minimal remaining bone, together with simultaneous implant placement may be a feasible treatment option as long as adequate primary stability can be ensured (11).

Wood and Moore (12) described two options for performing the window access, either using surgical hand pieces or modified high-speed hand pieces. Two main intra-operative complications that can easily happen are excessive bleeding and perforation of the sinus membrane. The use of piezoelectric technique significantly decreases the complications during window access through the lateral approach. An intact membrane is mandatory for stabilizing the graft and avoidance of any infectious pathology in the maxillary sinus (13-15). The probability of membrane perforation during osteotomy is minimized by selective cutting. Piezoelectric device allow selective cutting, where only mineralized structures are cut without damaging the soft tissues (1618).

Autogenous bone is almost the most promising material used to fill the area of the maxillary sinus that was created by sinus lift procedure. This is considered the gold standard in reconstructing the alveolar bone because it has osteogenic, as well as osteoinductive and osteconductive characteristics (19-21).

However, autogenous bone graft possesses some disadvantages and systemic limitations, such as the need for a second surgical site and occurrence of postoperative morbidity (22), many different biomaterials have been investigated for use in sinus augmentation including particulate alloplastic bone substitutes $(23,24)$.

The rapid and continuous development of biomaterials has improved the physical attributes and properties of different alloplastic bone substitutes to include novel characteristics such as the moldable putty consistency. A more viscid consistency of biomaterials used for augmenting the maxillary sinus could have a positive effect on the primary stability of an implant placed simultaneously with a maxillary sinus lift procedure.

Synthetic putty comprised of calcium phosphate and silica particles, and additive phase consisting of polyethylene glycol have been found to be successful when being used for maxillary sinus augmentation $(25,26)$.

Lundergen et al.(27), were the first to find that after cyst removal from the maxillary sinus, bone neoformation occurred in the region without any biomaterial being placed for vertical augmentation of the alveolar ridge. With the publishing of that study, a new concept appeared and other researchers have used this suggestion to observe bone neo-formation potential of the blood clot in the maxillary sinus. A "de novo" bone formation under the elevated schneiderian membrane during maxillary sinus lift procedures even in absence of graft material was proven clinically and experimentally (28-30).

The present study compared the outcome of sinus lift procedure with and without the use of moldable calcium-phosphate as filling material, both with simultaneous implant placement.

\section{MATERIALS AND METHODS \\ Study design:}

The study was performed as a randomized controlled clinical trial.

\section{Patients selection and evaluation:}

In this study 20 patients requiring dental implants rehabilitation in edentulous posterior maxillary region and elevation of the pneumatized maxillary sinus floor, were selected from the out-patient clinic of Oral and Maxillofacial surgery department Faculty of Dentistry, Alexandria University.

The inclusion criteria of this study were, patients having missing posterior maxillary teeth, the vertical height between the floor of the maxillary sinus and the alveolar crest ranged between 5 and $7 \mathrm{~mm}$, free from maxillary sinus pathologies, adequate oral hygiene, acceptable interarch space for the prosthesis, while the exclusion criteria were patients with systemic diseases that directly affect the surgical procedure and/ or the healing of the bone, immunocompromised statues, and alcoholism, psychiatric disorders and patients with parafunctional habits.

The patients included in the study were allocated randomly into two equal groups:

Group I: ten patients had sinus lift with piezosurgery together with simultaneous implant placement.

Group $\Pi$ : ten patients had sinus lift with pizeosurgery, moldable self-hardening biphasic calcium phosphate was the filling material with simultaneous implant placement.

\section{Informed consent:}

Appropriate institutional ethical clearance provided by the Faculty of Dentistry Alexandria University Ethical Committee, and written informed consents were presented by the patients. All patients were informed about the purpose of the study.

\section{Materials}

- Implants of TRI Neobiotech implant system (Neobiotech, Korea).

- Piezo-ultrasound surgery unit piezotome 2 (Acteon Co., UK).

- Easy graft, a moldable osteocondutive allograft formed of $60 \%$ hydroxylapatite and $40 \% \beta$-tricalcium phosphate (Easy-graft, Sunstar, Gruidor, Degradable solutions AG, Swizerlard).

\section{Method}

\section{Pre-surgical phase:}

Evaluation of all patients by taking their case history, clinical and radiographic examination using standardized panoramic X-rays and cone beam computed tomography CBCT (J. mortia, at 8mA, 90KV, Japan). (Fig.3a, 4a).

Ear, nose and throat (ENT) consultation was performed to exclude any pathology or inflammation related to the maxillary sinus before the operation.

Full arch maxillary and mandibular impressions were taken and a diagnostic wax-up was constructed on the study cast to fabricate a vacuum-formed stent for locating the osteotomy site during the surgery. (Fig. 2a) Surgical procedure: 
El Sadek et al.

Maxillary sinus lift with and without self hardening biphasic calcium phosphate

All the patients in the two groups were operated under local anesthesia and complete aseptic conditions. A pyramidal full thickness mucoperiosteal flap was performed distal to the canine area with a crestal incision located palatally in the edentulous area and vertical extension of the incision to the buccal vestibule using Bard Parker blade number 15. The flap was reflected exposing the alveolar bone. (Fig. 1a\& 2b).

Osteotomy of the buccal window was performed using the piezosurgery device (piezotome 2, Acteon Co., UK) followed by meticulous dissection of the sinus membrane.

(Fig. 1b\& 2c)

Drilling at the sites where implants were to be placed was done using Neobiotech implant drilling Kit. Implants (TRI Neobiotech implant system, Korea) (Fig. 1c) guided by the preformed surgical stent. Implants of appropriate size were placed (Fig. 1d\& 2d).in a selftapping fashion using a torque wrench.

In group I: No filling material was added in the periimplant space.

In group II: The sinus was augmented with moldable self-hardening biphasic calcium phosphate (Fig. 2e).

Flaps were placed back in position and sutured using 3-0 black silk suture material. (Fig. 1e,2f)

\section{Postsurgical instructions and medications:}

The patients were instructed to apply cold packs extraorally intermittently and to avoid hot drinks and food for the first 24 hours postoperatively, avoid eating hard food at the site of the surgery, avoid nose blowing and sucking with a straw.

\section{Postoperative medication included:}

Chlorhexidine mouth wash twice daily for the following 5 days, broad spectrum antibiotic Amoxicillin 875mg clavulanic acid $125 \mathrm{mg}$ tablets (Augmentin 1 gram tablet Glaxosmithkline group, co-Egypt) every 12 hours for five days to avoid postoperative infection.

Non steroidal anti-inflammatory analgesic in the form of Diclofenac potassium (cataflam 50mg tables, Novartis pharma, AG, Basle, Switzerland) 3 times daily for 1 week to avoid the occurrence of inflammation, edema and pain. Ephidrine nasal drops (Otrivin spray/ nasal drops 10ml, Novartis pharma, AG, Basle, Switzerland) for 5 days.

\section{Postoperative evaluation:}

The day after surgery all patients were examined weekly for the first month postoperatively.

\section{Clinical evaluation:}

Pain was evaluated using visual analogue scale (VAS) (31), wound dehiscence, nasal obstruction, detecting any signs or symptoms of infection. Implant stability was examined immediately postoperatively and after 6 months by using Osstell (Osstell co. Swedan).

\section{Radiographic evaluation}

Cone beam computed tomography (CBCT) was done immediately postoperative and at 6 months for both groups. The apparatus and the settings were kept the same during all the preoperative scans to evaluate the amount of vertical bone height gained, the change of bone density and the marginal bone loss postoperatively. (Fig. 3b,c \& 4b, c)

Prosthetic phase
Exposure of the implants site by punch technique was performed in the two groups. Placement of the super structure. (Fig. 5a, 6a)

Impressions were taken with the implants analogues in place. Definitive porcelain fused to metal crowns were inserted to all patient after 6 months for both groups (Fig. $5 b, 6 b)$.

\section{Stastical analysis of the data (32)}

Data were entered to the computer and analyzed using IBM SPSS software (package version.20.0. IBM corporation 1. New orchard Road, Armonk, New York, United States).

Quantitative data were presented using range (minimum and maximum), mean, median and standard deviation. The quantitative variables were tested for normality using Kolmogorov- Smirnov test, Shapiro-Wilk test and D Agstino test, significance of the obtained results were evaluated at the $5 \%$ level.

Figure (1): (A) A pyramidal full thickness mucoperiosteal flap (B) Lateral window (C) Drilling of the implant (D) Implant were placed (E) sutured of the flap.

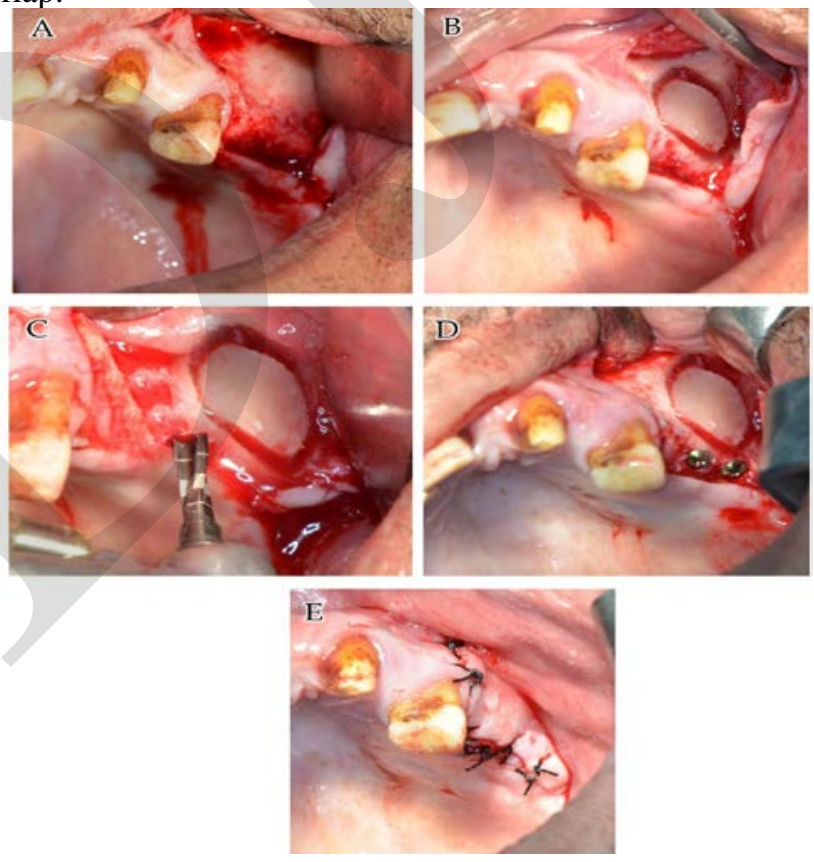

Figure (2): (A) study cast (B) A pyramidal full thickness mucoperiosteal flap (C) Lateral window (D) Implant were placed (E) sinus was augmented with biphasic calcium phosphate (F) sutured of the flap.

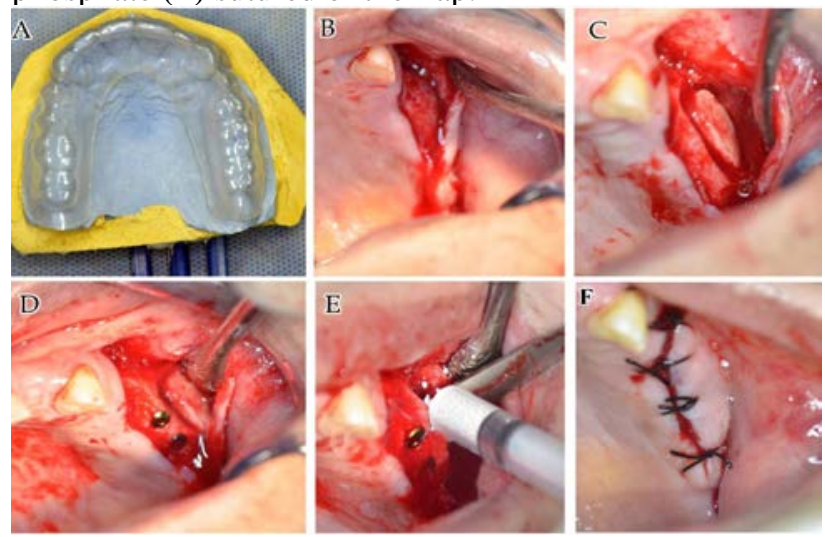


Figure (3): Radiographic evaluation, cone beam computed tomography (CBCT) (Group I) (A) preoperative (B) immediately postoperative (C) after 6 months.
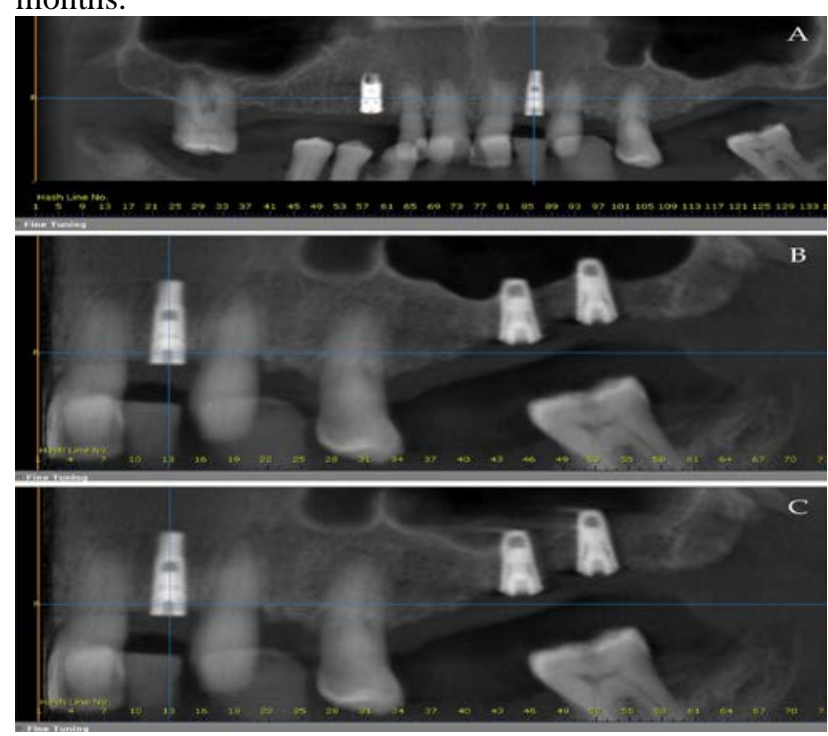

Figure (4): Radiographic evaluation, cone beam computed tomography (CBCT) (Group II) (A) preoperative (B) immediately postoperative (C) after 6 months.
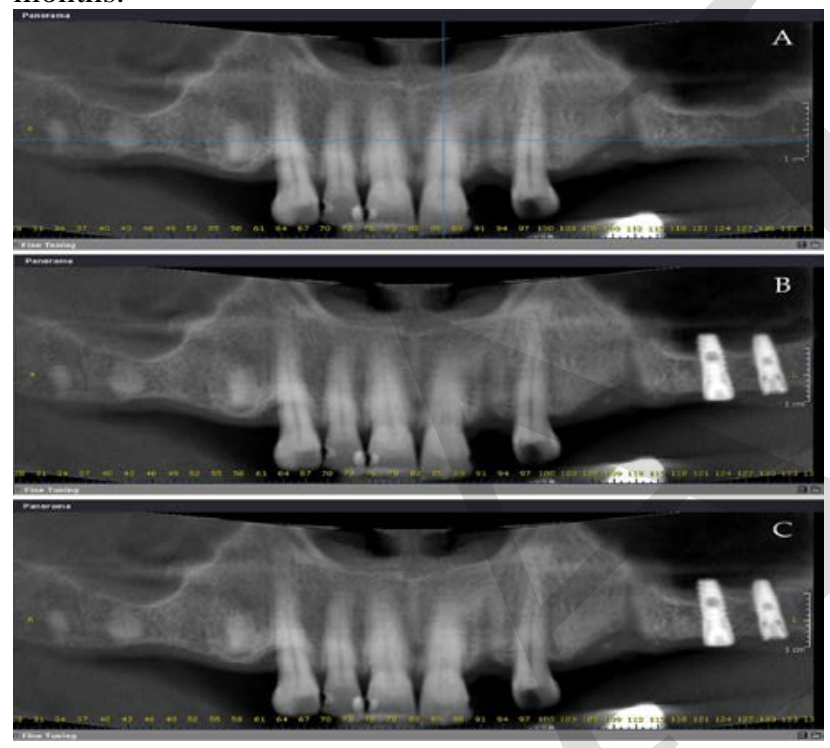

Figure (5): (Group I) (A) placement of the super structure (B) insertion of porcelain fused to metal crowns.

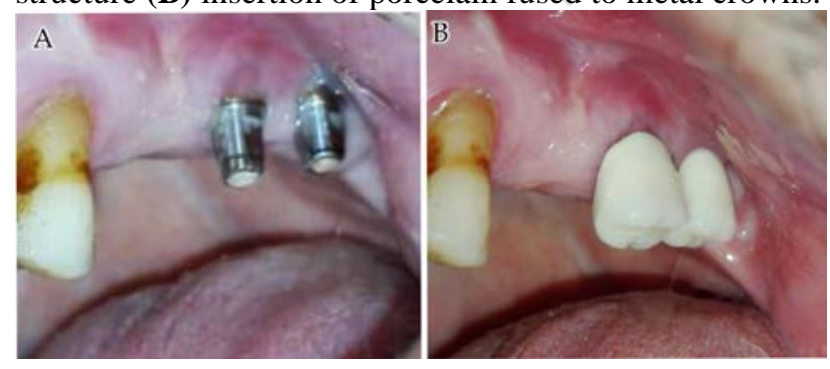

Figure (6): (Group II) (A) placement of the super structure (B) insertion of porcelain fused to metal crowns.
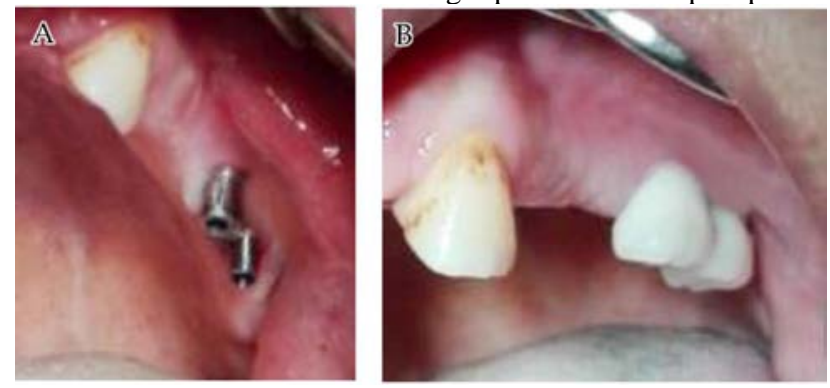

\section{RESULTS}

In this study, ten patients in group I had maxillary sinus lift, blood clot was the filling material together with simultaneous implant placement. In group II ten patients had maxillary sinus lift, moldable self hardening biphasic calcium phosphate was the filling material with simultaneous implant placement. The included patients were twelve males (60\% of patients) and eight females (40\% of patients) and the range of age was from $30-50$ years.

In group I the mean height of the alveolar ridge from the marginal crest to the maxillary sinus floor was $5.91 \pm 1.07 \mathrm{~mm}$ (Range $5.05-7.0 \mathrm{~mm}$ ), while in group II mean height of the alveolar ridge from the marginal crest to the maxillary sinus floor was $5.89 \mathrm{~mm} \pm 0.79 \mathrm{~mm}$ (Range 5.04-6.8mm).

The number of implants placed were twenty implants in group I patients and eighteen implants were placed in group II patients. The length of the implants in both groups ranged from $7-10 \mathrm{~mm}$.

Regarding the position of the implants, in group I, eight implants were placed in maxillary second molar area, ten implants were placed in maxillary first molar region and two implants in maxillary second premolar area. In group II, seven implants were placed in maxillary second molar region, eight implants in maxillary first molar region, and three implants in maxillary second premolar area.

\section{Postoperative evaluation}

\section{Clinical evaluation}

Postoperative pain evaluation in group I: six patients experienced mild pain (VAS=1) and four patients experienced moderate pain (VAS=2) at surgical site for 17 days duration.

In group II, seven patients experienced mild pain (VAS=1) and three patients experienced moderate pain $(\mathrm{VAS}=2)$ at surgical site for 1-5 days duration.

Wound dehiscence: in group I no wound dehiscence was observed in nine patients in all the clinical evaluation during the first month, one patient showed wound dehiscence at the first week clinical evaluation. In group II, no wounds dehiscence was observed during the followup period.

Regarding nasal obstruction, in group I, 2 patients complained during the 1st postoperative day and resolved within one week. In group II, one patient complained of nasal obstruction the 1st postoperative day and resolved within one week.

The number of implants placed were twenty implants in group I patients and eighteen implants were placed in group II patients. The length of the implants in both groups ranged from $7-10 \mathrm{~mm}$. 
El Sadek et al.

Maxillary sinus lift with and without self hardening biphasic calcium phosphate

Regarding the position of the implants, in group I, eight implants were placed in maxillary second molar area, ten implants were placed in maxillary first molar region and two implants in maxillary second premolar area. In group II, seven implants were placed in maxillary second molar region, eight implants in maxillary first molar region, and three implants in maxillary second premolar area.

Table (1): Comparison between the two groups according to bone density of the newly formed bone in Hounsfield unit (HU).

\begin{tabular}{|r|r|r|l|l||}
\hline $\begin{array}{r}\text { Bone density in } \\
\text { (HU) }\end{array}$ & $\begin{array}{r}\text { Group I } \\
(\mathrm{n}=20)\end{array}$ & $\begin{array}{r}\text { Group II } \\
(\mathrm{n}=18)\end{array}$ & $\mathrm{t}$ & $\mathrm{p}$ \\
\hline Pre-operative & $131.01-$ & $154.22-$ & & \\
Min. - Max. & 655.60 & 447.91 & & \\
& $343.57 \pm$ & $288.34 \pm$ & 1.218 & 0.231 \\
Mean \pm SD. & 167.20 & 114.68 & & \\
Median & 337.43 & 310.67 & & \\
\hline Immediate post- & & & & \\
operative & $276.20-$ & $299.80-$ & & \\
Min. - Max. & 989.28 & 916.44 & & \\
& $652.40 \pm$ & $623.16 \pm$ & 0.423 & 0.675 \\
Mean \pm SD. & 212.20 & 224.73 & & \\
Median & 653.20 & 630.98 & & \\
\hline months post- & & & & \\
operative & $855.05-$ & $616.68-$ & & \\
Min. - Max. & 1413.72 & 1253.93 & & \\
Mean \pm SD. & $1128.10 \pm$ & $1080.74 \pm$ & 0.743 & 0.462 \\
Median & 186.98 & 215.15 & & \\
\hline
\end{tabular}

$\mathrm{t}, \mathrm{p}$ : $\mathrm{t}$ and $\mathrm{p}$ values for Student t-test for comparing

between the two groups are statistically in significant

Table (2): Comparison between the two groups according to marginal bone loss after 6 months.

\begin{tabular}{|r|r|r|r|r||}
\hline $\begin{array}{r}\text { Marginal bone loss } \\
\text { after 6 months }\end{array}$ & $\begin{array}{r}\text { Group I } \\
(\mathrm{n}=20)\end{array}$ & $\begin{array}{r}\text { Group II } \\
(\mathrm{n}=18)\end{array}$ & $\mathrm{t}$ & $\mathrm{p}$ \\
\hline Min. - Max. & $0.40-$ & $0.50-$ & & \\
& 1.72 & 4.73 & & \\
& $1.15 \pm$ & $1.50 \pm$ & 1.120 & 0.269 \\
Mean \pm SD. & 0.46 & 1.32 & & \\
Median & 1.20 & 2.30 & & \\
\hline
\end{tabular}

$\mathrm{t}, \mathrm{p}$ : $\mathrm{t}$ and $\mathrm{p}$ values for Student t-test for comparing between the two groups are statistically in significant DISCUSSION

Maxillary posterior teeth loss usually leads to bone resorption and results in pneumatization of the maxillary sinus (4).

The maxillary edentulous area in many cases exhibit poor bone volume and therefore bone reconstruction is required, such as sinus augmentation before inserting dental implants (5).

The present study was designed to compare both clinically and radiographically, the out-come of sinus lift together with simultaneous implant placement using moldable, self hardening calcium phosphate, compared to that without filling material.

The initial bone height from the alveolar crest to the floor of the maxillary sinus that received the implants ranged from $5.04-6.70 \mathrm{~mm}$ (mean $\pm \mathrm{SD}, 5.96 \pm 0.79$ ). This is in agreement with a study conducted by Mardinger et al. (33) in 2011, the study compared the radiographic changes in dimensions of sinus graft height above and between placed implants, and evaluated the factors that caused these changes. 2 different grafting materials were used and also combination of the two materials. 92\% success rate was reported in patients with 1 to $3 \mathrm{~mm}$ of residual vertical bone height compared .In patients with residual bone height more than $4 \mathrm{~mm}$, the success rate was $98.7 \%$.

In this study, the maxillary sinus was accessed through lateral window approach in both groups. No implant failure was detected until the 6th month postoperatively.

This is in agreement with the results obtained by Wallace and Froum (34) in 2003, that stated a 91.8\% survival rate in their study.

The maxillary sinus was accessed through the lateral window osteotomy using the piezoelectric surgery to protect the soft tissues and also to make the patients' discomfort minimal. This is in agreement with Carini et al. (35), in 2014 they reported in their study that bone healing showed a reduced rate of bone loss when using piezoelectric instruments compared to the use of conventional devices, and also showed better healing quality due to the reduction of the patients' postoperative morbidity.

Autogenous bone has been considered the gold standard for bone grafting due to its osteogenic, osteoinductive and osteoconductive properties, and also due to the lack of immunogenic response (36). Meanwhile, it has several disadvantages including increased morbidity of the donor site, the need for a second surgery to harvest the graft and limited volume of the graft especially in case of augmentation of a large or severally pneumatized sinuses that's why biphasic calcium phosphate was used in this study.

Other grafting materials have been advocated to overcome these disadvantages. These materials include allografts, xenografts, and alloplasts or a mixing material together.

In 2004, Lundgren et al (37) introduced the graftless augmentation of the maxillary sinus. They elevated the sinus membrane and used the implants as tent poles to maintain the level of the elevated sinus membrane, without any grafting material being inserted. The hypothesis of this research was that the maintenance of the elevated space allows formation and stabilization of the blood clot and consequently bone formation in the elevated space. Several other studies (38) have concluded the efficacy of graftless sinus floor elevation as a reliable method for sinus augmentation. The main advantages of this method are that it eliminates any possibility of immunogenic response, reduced cost, reduced operation time, and the lack of any grafting procedure and therefore, reducing the patient's morbidity.

Easy graft material was used in group II. It is the first particulate alloplastic bone graft material that is designed to be directly syringed into the space to be augmented, hardening into a highly stable, porous scaffold in less than one minute. It is composed of betatricalcium phosphate granules coated with a 
biodegradable polymer called polylactide - coglycolide (PLAG) which is impregnated with N-methyl-2pyrrolidone (NMP) liquid activator called Biolinker to form a permeable, highly moldable material which hardens to form a stable, porous Scaffold by "washing out" the biolinker again from the PLGA- coating by blood-flow or rinsing with saline solution.

All implants in both groups were placed simultaneously with the maxillary sinus membrane lifting. New bone formation was evidenced and recorded in both groups at six months postoperatively. The increased bone density in both groups were found to be statistically insignificant $(p=0.462)$

The results obtained in this research, are in agreement with Lambert et al. (39), in 2010 compared, in a study on rabbits, the use of different materials as fillers in sinus augmentation, including the blood clot, autogenous bone and bovine hydroxyapatite (BHA): the three space-fillers caused bone formation. The authors concluded that the blood clot is a great growth factor carrier, that causes initially a faster and greater bone formation.

\section{CONCLUSION}

We concluded from this study that sinus lift without a filling material is a reliable technique with comparable results to that of sinus lift combined with easy-graft material regarding bone height, bone density and implant stability.

\section{CONFLICT OF INTEREST}

The authors informed that they have no conflict of interest.

\section{REFERENCES}

1. Browaeys H, Bouvy P, De Bruyn H. A literature review on biomaterials in sinus augmentation procedures. Clin Implant Dent Relat Res 2007;9:166-77.

2. Shulman LB, Jensen OT. Sinus graft consensus conference. Introduction. Int $\mathrm{J}$ Oral Maxillofac Implants 1998;13:5-6.

3. Geurs NC, Wang IC, Shulaman LB, Jeffcoat MK. Retrospective radiographic analysis of sinus graft and implant placement procedures form the academy of osseointegration consensus conference on sinus grafts. Int $\mathrm{J}$ Periodontics Restorative Dent 2001;21:517-23.

4. Jensen OT, Shulman LB, Block MS, Iacono VJ. Report of the sinus consensus conference of 1996. Int J Oral Maxillofac Implants. 1998;13:11-45.

5. Wheeler SL, Holmes RE, Calhoun CJ. Six-year clinical and histologic study of sinus-lift grafts. Int J Oral Maxillofac Implants. 1996;11:26-34.

6. Boyne PJ, James RA. Grafting of the maxillary sinus floor autogenous marrow and bone. J Oral Surg 1980;38:613-6.

7. Kent JN, Block MS. Simultaneous maxillary sinus floor bone grafting and placement of hydroxylapatite-coated implants. J Oral Maxillofac Surg 1989;47:238-42.

8. Mazor Z, Horowitz RA, Del Corso M, Prasad HS, Rohrer MD, Dohan Ehrenfest DM. Sinus floor augmentation with simultaneous implant placement using Choukroun's platelet-rich fibrin as the sole grafting material: a radiologic and histologic study at 6 months. J Periodontal 2009; 80:2056-64.

9. Del Fabbro M, Testori T, Francetti L, Weinstein R. Systematic review of survival rates for implants placed in the grafted maxillary sinus. Int Periodontics Restorative Dent 2004;24:656-77.

10. Van den Bergh JP, ten Bruggenkate CM, Disch FJ, Tuinzing DB. Anatomical aspects of sinus floor elevations. Clin Oral Implants Res 2000;11:256-65.

11. Cha HS, Kim A, Nowzari HS, Ahn KM. Simultaneous sinus lift and implant installation: prospective study of consecutive two hundred seventeen sinus lift and four hundred sixty-two implants. Clin Implant Dent Relat Res 2014;16:33747.

12. Wood RM, Moore DL. Grafting of the maxillary sinus with intraorally harvested autogenous bone prior to implant placement. Int J Oral Maxillofac Implants 1988;3:209-14.

13. Becker ST, Terheyden H, Steinriede A, Behrens E, Springer I, Wiltfang J. Prospective observation of 41 perforations of the Schneiderian membrane during sinus floor elevation. Clin Oral Implants Res 2008;19:1285-9.

14. Wallace SS, Mazor Z, Froum SJ, Cho SC, Tarnow DP. Schneiderian membrane perfornation rate during sinus elevation using piezosurgery: clinical results of 100 consecutive cases. Int J Periodontics Restorative Dent 2007:27:413-9.

15. Blus C, Szmukler-Moncler S, Salama M, Salama H, Garber D. sinus bone grafting producers using ultrasonic bone surgery: 5-year experience. Int J Periodontics Dent 2008;28:221-9.

16. Schaller BJ, Gruber R, Merten HA, Krushat T, Schliephake H, Buchfelder M. et al. Piezoelectric bone surgery: a revolutionary technique for minimally invasive surgery in cranial base and spinal surgery? Technical note. Neurosurgery 2005;57: E410.

17. Vercellotti T. Technological characteristics and clinical indications of piezoelectric bone surgery. Minerva Stomatol 2004;53:207-14.

18. Hoigne DJ, Stübinger S, Von Keanel O,Shamdasani S, Hasenboehler P. Piezoelectric osteotomy in hand surgery: first experiences with a new technique. BMC Musculoskelet 2007;7:36.

19. Liu Y, Möller B, Wiltfang PH, Terheyden H. Tissue engineering of a vascularized bone graft of critical size with an osteogenic and angiogenic factor-based in vivo bioreactor. Tissue Eng Part A 2014;20:318997.

20. Kim JW, Cho MH, Kim SJ, Kim MR. Alveolar distraction osteogenesis versus autogenous onlay bone graft for vertical augmentation of severely atrophied alveolar ridges after 12 years of long-term follow-up. Oral Surg Oral Med Oral Pathol Oral Radiol 2013;116:540-9.

21. Rickert D, Slater JJ, Meijer HJ, Vissink A, Raghoebar GM. Maxillary sinus lift with solely autogenous bone compared to a combination of 
autogenous bone and growth factors or (solely) bone substitutes. A systematic review. Int $\mathrm{J}$ oral Maxillofac Surg 2012;41:160-7.

22. Polo-Corrales L, Latorre-Esteves M, Ramirez-Vick JE. Scaffold design for bone regeneration. J Nanosci Nanotechnol 2014;14:15-56.

23. Wanger $\mathrm{W}$, Wiltfang $\mathrm{J}$, Pistner $\mathrm{H}$, Ploder $\mathrm{B}$, Chapman M, Schiestl N, et al. Bone formation with a biphasic calcium phosphate combined with fibrin sealant in maxillary sinus floor elevation for delayed dental implant. Clin Oral Implants Res 2012;23:1112-7.

24. Galindo-Moreno P, de Buitrago JG, Padial-Molina M, Fernández-Barbero JE2, Ata-Ali J, O Valle FHistopathological comparison of healing after maxillary sinus augmentation using xenograft mixed with autogenous bone versus allograft mixed with autogenous bone. Clin Oral Implants Res 2018;29:192-201.

25. Mahesh L, Salama MA, Kurtzman GM, Joachim FP. Socket grafting with calcium phosphosilicate alloplast putty: a histomorphometric evaluation. Compend Contin Educ Dent 2012;33:e109-15.

26. Kotsakis GA, Salama M, Chrepa V, Hinrichs JE, Gaillard P. A randomized, blinded, controlled clinical study of particulate anorganic bovine bone mineral and calcium phosphosilicate putty bone substitutes for socket preservation. Int $\mathrm{J}$ Oral Maxillofac Implants 2014;29:141-51.

27. Lundgren S, Andersson S, Sennerby L. Spontaneous bone formation in the maxillary sinus after removal of a cyst: coincidence or consequence?. Clin Implant Dent Relat Res 2003;5:78-81.

28. Ahn JJ, Cho SA, Byrne G, Kim JH, Shin HI. New bone formation following sinus membrane elevation without bone grafting: histologic findings in humans. Int J Oral Maxillofac Implants 2011;26:8390.

29. Altintas NY, Senel FC, Kayımaz S, Taskesen F, Pampu AA. Comparative radiologic analyses of newly formed bone after maxillary sinus augmentation with and without bone grafting. J Oral Maxillofac Surg 2013;71:1520-30.
30. De Oliveira GR, Olate S, Cavalieri-Pereira L, Pozzer L, Asprino L, de Moraes M, et al. Maxillary sinus floor augmentation using blood without graft material. Preliminary results in 10 patients. J Oral Maxillofac Surg 2013;71:1670-5.

31. Chang DJ, Bird SR, Bohidar NR, King T. Analgesic efficacy of rofecoxib compared with codeine/acetaminophen using a model of acute dental pain. Oral Surg Oral Med Oral Pathol Oral Radiol Endod 2005;100:e74-80.

32. Kotz S, Read CB, Vidakovic B. Encyclopedia of Statistical Sciences. N.J. Wiley - Interscience; 2006. pp33-59.

33. Mardinger O1, Chaushu G, Sigalov S, Herzberg R, Shlomi B, Schwartz-Arad D. Factors affecting changes in sinus graft height between and above the placed implants. Oral Surg Oral Med Oral Pathol Oral Radiol Endod. 2011 Jan;111(1):e6-11.

34. Wallace SS, Froum SJ. Effect of maxillary sinus augmentation on the survival of endosseous dental implants. A systematic review. Ann Periodontol. 2003;8:328-43.

35. Carini F, Saggese V, Porcaro G, Baldoni M. Piezolelectric surgery in dentistry: a review. Minerva Stomatol 2014;63:7-34.

36. Gazdag AR, Lane JM, Glaser D, Forster RA. Alternatives to autogenous bone graft: efficacy and indication. J Am Acad Orthop Surg 1995;3:1-8.

37. Lundgren S, Anderson S, Gualini F, Sennerby L. Bone reformation with sinus membrane elevation: a new surgical technique for maxillary sinus floor augmentation. Clin Implant Dent Relat Res 2004;6:165-73.

38. Car-Fuentes M, Machuca-Ariza J, Ruiz-Martos A, Ramos-Robles MC, Martinez-Lara I. Long-term outcome of dental implants after maxillary augmentation with and without bone grafting. Med Oral Patol Oral Cir Bucal 2016;21:e229.

39. Lambert F, Léonard A, Drion P, Sourice S, Layrolle $\mathrm{P}$, Rompen E. Influence of space filling materials in subantral bone augmentation: blood clot VS autogenous bone chips VS bovine hydroxyapatite. Clin Oral Tmplant Res 2011;22:538-45. 